\title{
O DOUTORADO QUE UNE SABEDORIA BÍBLICA E PROFECIA
}

The Doctorate the that Unites Biblical Knowledge and Prophecy

Marcelo Barros *

Caríssimo Padre Geraldo De Mori, excelentíssimo reitor dessa Faculdade de Filosofia e Teologia. Caríssimos professores e alunos aqui presentes, irmãos e irmãs, parentes e amigos de Luiz Alberto Gómez de Souza, nosso novo doutorando em Teologia e, finalmente, querido irmão Luiz Alberto.

Ter sido escolhido para proferir aqui essa Laudatio é para mim imensa honra, que só aceitei por causa da profunda amizade de vida e aliança fraterna que, há quatro décadas, me liga a Luiz Alberto. Ao me convidar, ele fez questão de dizer que me havia escolhido por esse critério: o da amizade. Por isso, logo aceitei. Por falar em amizade, uma das páginas mais primorosas sobre isso vem de Saint-Exupéry no Pequeno Príncipe. É o encontro do principezinho com a raposa. Ele revela à sua nova amiga que vem de outro planeta. E a raposa, muito interessada, pergunta:

- Nesse seu planeta, há caçadores?

E o principezinho responde: - Não.

E ela reage: Que beleza! Mas, aí se lembra de perguntar:

- E tem galinha?

Ele responde: - Também não.

Ela baixa a cabeça e conclui: "- Nesse mundo nada é perfeito!"

* Palestra proferida dia 26 de outubro de 2018, por ocasião da recepção do título de Doutor Honoris Causa pela FAJE de Belo Horizonte. 
Se fôssemos atualizar essa parábola, eu diria a Luiz Alberto:

- Pois é, você escolheu um amigo e terá aqui agora a Laudatio feita em estilo de testemunho. Por outro lado, como nada é perfeito, ela será construída academicamente, como, provavelmente, seria o normal em uma Faculdade como essa. E vocês, que me ouvem aqui agora, me perdoem, se nesse testemunho, ao falar de Luiz Alberto, precise como referência minha experiência de encontros e de convivência com ele e Lúcia. Por isso, talvez, uma vez ou outra, esse testemunho possa parecer autorreferencial, o que gostaria de evitar. Se soar autorreferencial, me perdoem e lembrem do que dizia o Pequeno Príncipe: "As palavras são fonte de mal-entendidos".

Tive a graça de conhecer Luiz Alberto há 40 anos em 1978, em uma Assembleia nacional do Conselho Indigenista Missionário (CIMI) em Cuiabá, da qual fomos assessores. Um ano depois, nos reencontramos em uma assembleia nacional da Comissão Pastoral da Terra (CPT), em Goiânia. E, desde então, se deu entre nós uma amizade que só foi se aprofundando com o tempo. É uma verdadeira aliança de vida fraterna que Deus foi ampliando e, hoje, se constitui como verdadeira comunidade de vida fraterna para mim. De fato, vivo com Luiz Alberto e Lúcia, Pedro Ribeiro de Oliveira e Tereza e outros irmãos e irmãs o que, na linguagem de um grande espiritual dos primeiros anos do Ecumenismo em Lyon, o padre Paul Couturier, poderíamos chamar "Um mosteiro invisível espalhado pelo mundo" ou o que, hoje, alguns orientais chamam a Monasticidade interiorizada.

\section{Os primeiros impactos do doutorado laical}

Quando em 1978, encontrei Luiz Alberto, já o conhecia de nome e de livro. Tinha 20 anos. Estava concluindo o noviciado beneditino no mosteiro de Olinda, quando me deram o livro Os cristãos e o mundo, um dos primeiros de Luiz Alberto. Ele já vinha da experiência de coordenação e assessoria da JUC internacional e da JUC brasileira (tinha muito mais estrada rodada do que eu). Naquele livro, descobri alguém que ia além da definição restrita do que os documentos eclesiásticos, desde João Paulo II, chama de Christi fideles laici. Pelo fato de romper com a clássica separação entre sagrado e profano e por se situar como sendo Igreja em pleno mundo, Luiz Alberto recusa a noção clássica de leigo. O que caracteriza o ser cristão é pertencer ao povo de Deus. No século IV, a Didascalia, um importante documento da Igreja da Síria afirmava: "Vós também, leigos, Igreja eleita de Deus, escutai isso: em primeiro lugar, Igreja quer dizer povo. Sois a santíssima Igreja Católica, o sacerdócio real, o povo adotado, a grande assembleia, a esposa adornada para o Senhor Deus" (Didascalia II, 26, 1 apud BOUGEOIS, 2004, p. 1012). 
Assim, nas Igrejas antigas, leigo designava "o povo consagrado, naquela época, em oposição aos povos profanos" (CONGAR, 1953, p. 19). Todo o Cristianismo tinha um caráter especificamente laical. Como toda pessoa batizada é consagrada, todos/as são de Deus e podem abençoar, consagrar e assim por diante... É claro que no século XX, somos chamados a superar a divisão entre o povo de Deus consagrado na Igreja pelo batismo e os povos do mundo que, antigamente, eram considerados pagãos. Já em 1937, no campo ecumênico, o teólogo e pastor $\mathrm{J}$. H. Oldham, em preparação à conferência mundial de Oxford sobre Igreja, Comunidade e Estado, afirmava: "Se a Igreja quiser ser uma força eficaz na esfera social e política, nossa primeira tarefa deve ser laicizar nosso pensamento sobre ela (a Igreja). Estamos diante de uma grande tarefa histórica - a tarefa de restaurar a unidade entre culto e ação social e política" (ADLER; KATONEENE, 2005, p. 699).

$\mathrm{O}$ que significa concretamente laicizar o nosso pensamento sobre a Igreja? e "convocar as forças leigas do Cristianismo"? Mais tarde, na época em que Luiz Alberto escreveu $O$ cristão e o mundo, no Conselho Mundial de Igrejas, o mesmo pastor Oldham afirmará: "A redescoberta da missão e da responsabilidade dos leigos foi provavelmente o aspecto mais importante da renovação da Igreja nas décadas de 1950 e 1960" (loc. cit.).

Em 1972, em uma alocução aos membros dos Institutos Seculares em Roma, o papa Paulo VI afirmou: "A Igreja (toda) tem uma autêntica dimensão secular, inerente à sua íntima natureza e missão, cuja raiz mergulha no mistério da encarnação de Jesus" (PAULO VI, 1972, p. 2018).

É claro que a divisão da Igreja em classes e o surgimento dos ministérios ordenados em uma linha que é herança do sacerdócio da antiga religião imperial romana, legitimado e sacralizado pela noção do sacerdócio aarônico e levítico do primeiro Testamento já tinha entrado nas Igrejas desde ao menos o final do século I.

Atualmente, o papa Francisco repete sem cessar que o Clericalismo é uma doença grave e dá ele mesmo um testemunho forte na direção contrária. $\mathrm{Na}$ Constituição Apostólica Veritatis Gaudium, sobre as universidades e institutos de formação teológica, escreveu:

Na verdade, hoje em dia, a exigência prioritária é que todo o Povo de Deus se prepare para empreender, 'com espírito', uma nova etapa da evangelização. Isto requer 'entrar decididamente em um processo de discernimento, purificação e reforma'. [...] Esta tarefa enorme e inadiável requer, no nível cultural da formação acadêmica e da investigação científica, compromisso generoso e convergente em prol duma mudança radical de paradigma, ou melhor - permitam-me dizê-lo - para 'uma corajosa revolução cultural'. A esse compromisso, a rede mundial de Universidades e Faculdades eclesiásticas é chamada a prestar o 
decisivo contributo de fermento, sal e luz do Evangelho de Jesus Cristo e da Tradição viva da Igreja, sempre aberta a novos cenários e novas propostas (n. 3).

Infelizmente, essa divisão entre clérigos e leigos faz parte da própria estrutura de um Catolicismo que ainda divide os batizados em classe e vê Deus não como Amor sem limites e sim como poder sagrado. Agora, ao outorgar esse título de Doutor Honoris Causa a Luiz Alberto, vocês fazem algo semelhante ao que o papa Francisco fez no domingo 14 de outubro. Ao canonizar Monsenhor Romero, o papa reconheceu publicamente o que grande parte dos cristãos da América Latina já sabia e proclamava: desde os anos 80, Romero é San Romero de América. Aqui, ao outorgar o título de Doutor Honoris Causa em Teologia a Luiz Alberto, vocês, de certa forma, reconhecem algo que ele já é e já vive, ao menos, desde os anos 60. Todos que o conhecem profundamente sabem que, durante todos esses anos, ele se constituiu como verdadeiro doutor da fé, ou mesmo como a Igreja chama seus mestres mais insignes: doutor da Igreja.

\section{Nós o procuramos porque antes Deus nos procurou...}

E eu queria destacar duas coisas importantes nesse itinerário de Luiz Alberto. Primeiramente, uma dimensão muito bíblica: não foi tanto Luiz Alberto que procurou ou se candidatou a esses serviços eclesiais. Ele foi procurado, e de certa forma, algumas vezes, quase empurrado para isso. Só podemos pensar que foi assim, quando, em 1959, apenas um mês depois dele e Lúcia terem noivado, ele teve de deixá-la para morar em Paris e assumir a coordenação da Juventude Estudantil Católica (JEC) internacional (GÓMEZ DE SOUZA, 2015, p. 63 e 65). Depois quando menos de um mês do nascimento de Sílvia, a primeira filha, teve de deixar Lúcia em Paris com a criança e ir para Gana, para um encontro internacional da Ação Católica na África (GÓMEZ DE SOUZA, 2015, p. 67).

Do mesmo modo, quando se encerrou o Concílio Vaticano II, em 1965, Dom Helder Câmara estava convicto de que deveria já ir preparando um novo Concílio. Nos anos 80, ele escreverá uma carta a seu amigo Jerónimo Podestá, bispo argentino casado com Clelia Luro. Nessa carta,

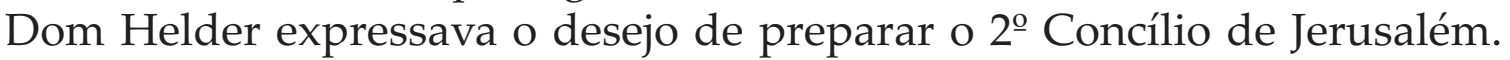
Ele não pensava em um concílio em Jerusalém e sim de Jerusalém, por retomar o encontro dos apóstolos em Jerusalém para abrir a fé a outras culturas (At 15). Dom Helder estava convencido de que hoje, a Igreja Católica, para ser católica, terá de se desocidentalizar (LURO, 2002, p. 100-102). Isso foi nos anos 80.

Em 1965, Dom Helder ainda pensava em um Vaticano III. Chamou Ivan Illich para coordenar os trabalhos preparatórios, a partir dos seus dois 
centros, o Centro de Formação Intercultural (CENFI) instalado em Petrópolis, e o Centro de Cuernavaca no México. Quando Ivan pediu a Dom Helder um leigo brasileiro que pudesse, em Cuernavaca, coordenar esse serviço de preparação ao novo Concílio, Dom Helder não hesitou. Indicou logo Luiz Alberto. Lá se foram Luiz Alberto, Lúcia e os filhos a morar no México (GÓMEZ DE SOUZA, 2015, p. 120).

Pouco depois dessa época, eu ainda não conhecia pessoalmente Luiz Alberto, ao menos uma vez, em um encontro do secretariado arquidiocesano de Pastoral no Recife, ouvi Dom Helder afirmar que, para ele, Luiz Alberto era um dos bispos leigos do Brasil. Outro era Dr. Alceu Amoroso Lima e havia ainda outros nomes que não cito aqui para não esquecer ninguém. Mas, esse modo de Luiz Alberto viver sua vocação eclesial é mais ou menos constante em seu caminho. Se eu fosse especificar melhor o título do seu livro mais recente, eu insistiria que ele não é apenas o andarilho entre duas fidelidades: a Religião e a Sociedade. De fato, o título que Dom Helder lhe deu de bispo leigo define que ele é pontífice, construtor de pontes entre antagonismos aparentemente opostos e irreconciliáveis. Ele sempre procurou construir pontes:

1 - entre o Cristianismo da Libertação, vivido pelas comunidades cristãs de base e os movimentos sociais,

2 - ponte entre a realidade eclesial e cultural brasileira e a melhor inteligência do Cristianismo europeu. Foi com Luiz Alberto que aprendi a valorizar Chesterton com seu detetive o padre Brown, George Bernanos e o seu Soul le Soleil de Satan e mesmo mais tarde o seu Diário de um pároco de Aldeia, Leon Bloy, peregrino do Absoluto, Jacques Maritain e Raíssa, Emmanuel Mounier e o Personalismo e outros autores. Antes eu os ouvia, me perdoem a expressão, da boca de gente de direita, o que me fazia usar um filtro para essas leituras ou citações.

3 - ponte entre uma visão transformadora do mundo e uma superação de todos os dogmatismos religiosos, sociais e políticos.

Foi Luiz Alberto que me ajudou a estabelecer pontes com esses diversos pensamentos e propostas, com todas as suas diferenças. Ele viveu e vive como andarilho entre não apenas duas fidelidades, mas múltiplas, uma inserção em muitos mundos culturais e sociológicos que ele sempre conseguiu dialogar e administrar. Quem o conhece mais profundamente sabe que nem sempre essa fidelidade é calma e harmoniosa. Às vezes, toma formas contundentes e, às vezes, mesmo provocadoras. Mas, é como a atividade dos profetas. Não somente evita as rupturas, como também busca sempre o diálogo e a inserção de elementos que aparentemente seriam opostos. 


\section{Um doutor de uma nova Teologia Apofática Latino- americana}

Na história da nossa Igreja Ocidental, até agora ainda se tem valorizado pouco a Teologia Apofática, aquela que respeita a kenosis Divina e o mandamento do Sinai: "Não pronunciarás o Nome" (Ex 20, 7).

No século IV, em seu livro "A vida de Moisés", São Gregório de Nissa afirmava: "Os conceitos criam ídolos de Deus; somente a admiração pode conhecer algo". Desde que conheço Luiz Alberto, o vejo viver esse caminho de testemunhar Deus como Amor em muitas instâncias da Igreja e do mundo. $\mathrm{O}$ modo como ele exerceu a assessoria em tantos organismos ligados à Igreja, mesmo na época, em que, como diretor do Centro de Estatísticas Religiosas e Investigações Sociais (CERIS), participava de todas as assembleias da Conferência Nacional dos Bispos do Brasil (CNBB), sempre foi de alguém que vivia "A mundanidade de um Cristianismo adulto", expressão do pastor e teólogo alemão Dietrich Bonhoeffer no campo de concentração nazista, esperando o martírio. Em uma de suas Cartas de Prisão, Bonhoeffer nos ensinava:

Diante de Deus e com Deus, vivemos sem Deus. Deus permite ser expulso do mundo até a Cruz". Mas é um paradoxo que, a nós, crentes, não nos afasta dele: "Deus é impotente e fraco no mundo e é exatamente assim que Ele está ao nosso lado e nos ajuda. [...] Mais tarde compreendi e experimento ainda até a presente hora, que só na dimensão da vida aqui e agora, é que podemos aprender a crer. Quando desistimos completamente de fazer algo importante de si mesmo [...] Isso significa viver plenamente as tarefas, problemas, sucessos e fracassos, experiências e perplexidades. [...] Só assim, nos tornamos cristãos verdadeiramente adultos. Jamais no tornaremos arrogantes com os sucessos, nem desalentados com os fracassos, se sofremos com Deus na vida presente. (1968, p. 173; 178).

O Cristianismo a-religioso é, portanto, "um Cristianismo não da fuga, mas da fidelidade ao mundo, um Cristianismo a ser vivido na responsabilidade, na participação e na solidariedade" (GIBELLINI, 2010, p. 83). É esse título de Doutor Honoris Causa que Luiz Alberto recebe hoje, como doutor na fé vivida na "humanidade de um Cristianismo adulto".

Luiz Alberto vive isso recriando a ponte entre esse pensamento de Bonhoeffer, nascido e nutrido na Europa já imersa no clima da secularização ocidental e uma América Latina tão diferente e original que é uma espécie de Bahia de todos os santos e todos os Orixás e Encantados.

É nesse mundo que Luiz Alberto tem exercido esse doutorado laical e como Igreja em saída. Nem se pode dizer que Luiz Alberto sempre viveu a Igreja em saída, porque nunca teve realmente de sair - sair de onde? - se ele sempre foi do mundo como ele é. É nesse mundo, muitas vezes, sem 
rumo que Luiz Alberto revive o que no século IV, Santo Agostinho dizia: "A história está grávida de Cristo". Luiz Alberto vive isso hoje de forma mais macro-ecumênica, acompanhando essa gravidez, como kenosis do Espírito.

\section{Ponte para a Teologia da Libertação}

Penso que conheci Gustavo Gutiérrez em 1986 em um curso informal para bispos, promovido a cada ano pelo Centro Ecumênico de Serviços a Evangelização e Educacão Popular (CESEEP). Tenho a impressão de que Gustavo criou uma amizade pessoal comigo por saber que me apresento como Teólogo da Libertação nas bases e das bases, já que admiro e procuro valorizar ao máximo a Academia, mas nunca foi o meu mundo cultural. Pode ser que tenha sido isso que o fez se aproximar mais de mim. Mas, eu suspeito que o mais decisivo mesmo foi quando lhe disse que era amigo de Luiz Alberto e Lúcia. Lembro-me que, em janeiro de 1991, desci no aeroporto de Iguazu na Argentina para dar um curso bíblico a agentes de base daquela região do país. Ao chegar ao aeroporto, minha surpresa foi encontrar além do irmão que foi me buscar para me levar ao curso, Gustavo que me esperava e me disse: "como tenho de viajar mais tarde, quis vir logo para ainda encontrar você e podermos conversar ao menos um pouco". Fomos comer alguma coisa na lancheria do aeroporto e a primeira coisa que ele me perguntou foi: "como vão nossos amigos Luiz Alberto e Lúcia"?

Essa relação de amizade e parceria com Gustavo, com Otto Maduro e outros irmãos e irmãs da Teologia da Libertação, sem dúvida, sempre têm sido fecundos para os dois lados. Luiz Alberto contribui com uma sensibilidade que é própria dele e cada teólogo tem contribuído e enriquecido de conteúdo esse doutorado que hoje vocês aqui reconhecem e outorgam oficialmente.

\section{Doutor de uma espiritualidade macro-ecumênica}

E como não é Luiz Alberto que busca e sim é conduzido a estabelecer pontes, em sua vida e de forma muito laical, também estabeleceu pontes na espiritualidade inter-religiosa ou macro-ecumênica.

Ainda nos anos 90, os três filhos de Luiz Alberto aderiram à Religião do Santo Daime, no Centro Eclético da Fluente Luz Universal Raimundo Irineu Serra (CEFLURIS), Vila do Céu do Mapiá, na Floresta Nacional do Purus no Acre. Lúcia, com sua sensibilidade de mãe, desde logo foi capaz de fazer a peregrinação e reencontrar os filhos nessa nova paisagem espiritual, para os pais tão diversa e aparentemente distante. Luiz 
Alberto também teve abertura interior para empreender com seus filhos esse Êxodo nem sempre fácil para um católico convicto como ele. De fato, pôs o coração na estrada, como sempre fez esse andarilho espiritual. No entanto, a inteligência racional no início teve alguma dificuldade em acompanhar a inteligência cordial, a primeira. E com um respeito imenso pela consciência dos filhos e em uma total atitude de confiança no discernimento deles, Luiz Alberto enfrentou uma verdadeira batalha interior até conseguir sintetizar tudo. Quando ocorreu o casamento de um dos filhos, me ofereci para acompanhá-lo ao Acre e participar da festa do casamento, o que de última hora, não aconteceu por motivos alheios à nossa vontade. Mas, eu estava junto com ele nesse diálogo interior que ele até hoje aprofunda e faz dele merecedor do título de Doutor Honoris Causa em Teologia, mas também em Macro-ecumenismo, para usar a expressão que o nosso querido profeta Dom Pedro Casaldáliga consagrou no $1^{0}$ encontro internacional da Assembleia do Povo de Deus (APD) em Quito em 1992 para caracterizar um ecumenismo não apenas de Igrejas e de religiões, mas uma ecumenicidade no caminho do reino de Deus e a partir do testemunho do reino.

\section{Doutor da Amizade Espiritual}

Antigamente, se dava um título que era honoris causa mas dava a cada doutor da Igreja uma característica: doctor angelicus, doctor seráfico, doctor marianus, e assim por diante. Se eu fosse dar um título a Luiz Alberto como doutor da Igreja, eu diria "Doutor da Amizade".

No século XII e XIII, os beneditinos cistercienses desenvolveram uma verdadeira Teologia da Amizade. Entre eles Elredo de Rievaulx (1110-1167), na Inglaterra) foi o que mais explicitou isso em um verdadeiro Tratado espiritual da Amizade (Braceland, 2010). Ele ensinava que irmão e irmã temos de ser de todo mundo. Viver a irmandade universal é nossa vocação. Agora dentro da irmandade ampla e irrestrita, a amizade a pessoa escolhe e essa escolha pode e deve ser espiritual ou podemos dizer teologal, testemunho do Amor de Deus Amigo ou Amiga da humanidade.

Penso que Luiz Alberto é das pessoas que mais soube retomar essa espiritualidade da amizade vivida na cotidianidade e secularidade da vida de hoje. Na forma de viver isso, Luiz Alberto mesmo sem ter nunca escrito sobre isso, revela e testemunha que, no debate epistemológico sobre a Teologia na América Latina, Jon Sobrino tem toda razão quando insiste que a Teologia, mesmo devendo sempre basear-se e se centrar na intelligentia fidei, deve buscar cada vez mais e principalmente a intelligentia amoris. Não se trata de Teologia 1 e Teologia 2, nem de Teologia da Libertação ou da Amizade Libertadora, no genitivo. É sim no próprio modo de conceber 
e fazer a Teologia que ela se torna, a partir da fé, a busca da compreensão e do como viver mais profundamente o amor solidário (AQUINO JUNIOR, 2012).

\section{Os sinais da hora dessa cerimônia.}

Essa cerimônia na qual a Faculdade Jesuíta de Filosofia e Teologia (FAJE) dá a Luiz Alberto o título de Doutor Honoris Causa é justa e oportuna, mas agora nesse momento em que vivemos no Brasil é uma resposta urgente e necessária aos sinais dos tempos ou mais concretamente ainda aos sinais da hora em que vivemos.

Não vou discorrer aqui sobre esse momento político porque todos nós estamos nele mergulhados e já temos muitas análises profundas e pertinentes. O que, no plano da Teologia, me parece importante perguntar é: o que fizemos da fé, da formação das nossas comunidades e da própria Teologia da Igreja para que o Brasil e, de certa maneira, mesmo o mundo tenham chegado a esse ponto? Ou será que não tem nada a ver uma coisa com a outra? Como tenho citado aqui Bonhoeffer e como pioneiro e mártir de uma teologia da resistência e da libertação, vale a pena lembrar que o primeiro adversário de Bonhoeffer não foi o poder nazista do Estado. Foi o conselho de pastores da sua Igreja e as forças das outras Igrejas que se constituíram como uma espécie de Cristofascismo ou de legitimação do autoritarismo racista e cruel do Estado, na linha do que a velha teologia da Cristandade considerava importante para os interesses da Igreja confundida com o próprio reino de Deus.

No final dos anos 30, na Alemanha, a preocupação de Bonhoeffer era teológica e pastoral, mas a ação era eminentemente política (BONHOEFFER, 2002, p. 59).

De outro modo e em outro estilo, talvez tenhamos mesmo de pensar no Brasil de hoje uma Igreja confessante e claramente profética. Provavelmente, não será mais como nos anos de Medellín e na década de 70, um processo coordenado por bispos iluminados (temos alguns, mas são poucos e nessa conjuntura, não sei se aceitam isso). Será a volta de doutores da Igreja no âmbito do laicato e nesse sentido, esse doutorado de Luiz Alberto é significativo e profético. Ele abre mais e mais os portões já abertos da FAJE ao mundo real e confuso em que vivemos. Abre a universidade às ruas e aos militantes que precisam do apoio e da parceria da Universidade para aprofundar e ir gestando novas ações de resistência e de gravidez de um novo modo de ser Igreja, não mais apenas como as Comunidades Eclesiais de Base (CEBs) afirmavam no começo dos anos 80, mas a partir do que o Espírito diz, hoje, às Igrejas e ao mundo. 
Penso que a primeira coisa a fazer nesse caminho será nos abrir mais e mais a um diálogo criativo e corajoso com toda a humanidade que estiver nesse processo da gravidez de um mundo novo.

Em primeira instância, e não em última, nascemos todos autocentrados. Se, agora, a sociedade brasileira se encontra contaminada pelo vírus da intolerância e até do ódio às esquerdas há muitas razões, externas e internas. No entanto, sem dúvida, nossas Igrejas e instituições educacionais não têm conseguido cumprir sua missão de educar mais profundamente a consciência e a sensibilidade das pessoas e dos grupos para nos ajudar a sair da prisão do ego e nos educar para amar. Por isso, são necessárias práticas educativas que infundam valores altruístas, gestos solidários, ideais sociais pelos quais a vida ganha sentido e o martírio deixa de ser apenas uma forma de morrer para ser uma forma de viver o testemunho do evangelho do reino. A mais profunda educação suscita nas pessoas o espírito crítico e a militância transformadora para o desafio permanente de aprimorar os sistemas sociais e políticos no sentido do amor solidário, da igualdade social e da justiça.

Caminhar nesse sentido implica vencer alguns desafios da atual conjuntura. O primeiro deles é superar o avassalador processo neoliberal de desistorização da história. Sem perspectiva histórica não há consciência nem projetos políticos humanizadores.

Em uma sociedade assim, cada vez mais se torna atual a tese de Theodor Adorno de que o desafio mais urgente da educação hoje no mundo é desbarbarizar a sociedade. Esse processo humano tem de ser central no esforço educativo e de toda civilização que quiserem ir além dos ensinamentos técnicos para atingir uma formação integral.

Já em 1965, Paulo Freire escrevia:

O ser humano é um ser de relações e não só de contatos. Não apenas está no mundo, mas com o mundo. Estar com o mundo resulta de sua abertura à realidade, que o faz ser o ente de relações que é. (...) No jogo constante de suas respostas, no próprio ato de responder, a pessoa vai mudando a si mesma. Organiza-se. Escolhe a melhor resposta. (...) Ademais, o ser humano é capaz de transcender. A sua transcendência, acrescente-se, não é um dado apenas de sua qualidade "espiritual" (...). A sua transcendência está também para nós, na raiz de sua finitude. Na consciência de ser inacabado e de saber que a sua plenitude se acha na capacidade de amar. Isso ocorre na ligação do ser humano com seu Criador, ou para os que não creem em Deus, na relação íntima e misteriosa com o mistério mais profundo que dá sentido à vida (1967, p. 39- 40).

Penso que essa intuição de Paulo Freire, é profundamente posta em prática por Luiz Alberto, principalmente no exercício permanente de sua função de educador e que ele vai realizando em cada artigo que escreve e que se espalha pelo Brasil. 
Em um de seus livros, Dom Hélder Câmara conta que, em um campo de concentração nazista, foi encontrado um instrumento de suplício, um chicote, no qual, por zombaria, estava escrito um nome: diálogo. Ele comentava:

Isso que os totalitários não entendem, repelem e tentam cobrir de ridículo deve ser para nós uma herança sagrada. Nessa sociedade que escuta tão pouco, devemos nos constituir como discípulos do diálogo. (...) O diálogo ajuda-nos a conhecer nossas verdadeiras medidas. Impede que nos fechemos em nosso egoísmo. Abre-nos ao outro e a Deus (CÂMARA, 1968, p. 90-91).

Na tradição judaica, uma velha história conta que, em uma noite, na sinagoga, alguns homens estão sentados à espera do novo dia. Um velho sábio encontra-se rodeado por alguns discípulos. Então, o sábio pergunta:

- Quando é que nós conseguimos reconhecer o momento em que a noite se completa e o novo dia desponta?

Um discípulo toma a palavra e diz: - Quando as estrelas desaparecem no céu e a terra passa a ser acariciada pelos raios do sol.

- Não, responde o mestre.

- Então, quando conseguimos distinguir à distância, sem qualquer dificuldade, um cão de um carneiro.

- Não, diz de novo o mestre.

- Mas quando então? Perguntam em conjunto os discípulos.

Depois de um instante de silêncio, o velho sábio responde:

- Tu reconhecerás o momento em que o dia desponta quando, contemplando $o$ rosto de um homem qualquer, nele reconheceres o teu próprio irmão. Caso contrário, no teu coração será ainda noite (DUCROT, 2007, p. 26).

Essa história nos confirma o pensamento de outro grande educador que partiu do nosso meio antes do combinado e que quero ainda homenagear aqui. Ele afirmou: "Para ensinar, você só precisa saber. Para educar, precisa ser" (Ruben Alves).

Isso é o que define Luiz Alberto como doutor da fé, doutor de uma teologia que sai dos muros eclesiásticos para o mundo laical e doutor dessa dimensão teologal da amizade que abrange o mundo inteiro.

Muito obrigado!

\section{Referências}

ADLER, E.; KATONEENE, J. Laicato. In: LOSSKY, N. et al. Dicionário do Movimento Ecumênico. Petrópolis: Vozes, 2005. p. 698-703. 
AQUINO JUNIOR, F. Teoria teológica, praxis teologal. São Paulo, Paulinas, 2012.

BONHOEFFER, D. Resistência e Submissão. Rio de Janeiro: Paz e Terra, 1968.

. Ética. 6.ed. Sinodal: São Leopoldo, 2002.

BOUGEOIS, D. Leigo/Laicato. In LACOSTE, J.-Y. (Org.). Dicionário Crítico de Teologia. São Paulo: Paulinas/Loyola, 2004. p. 1011-1016.

CÂMARA, H. Revolução dentro da Paz. Rio de Janeiro: Sabiá, 1968.

DUCROT, B. Sobre a reconciliação em Angola. Omnis Terra, n. 116, ano XIII, jan. 2007. p. 13.

CONGAR, Y. Jalons pour une Théologie du Laïcat. Paris : Le Cerf, 1953. p. 19.

DE RIEVAULX, E. Spiritual Friendship. LAWRENCE BRACELAND (Ed.) Marshal L. Dutton Cistercian Fathers, serie 5 (Colleville: Cistercian Publications, 2100).

FREIRE, P. Educação como Prática da Liberdade. Rio de Janeiro: Paz e Terra, 1967.

GIBELLINI, Rosino, Breve história da teologia do século XX. Aparecida: Santuário, 2010. . A teologia do século XX. 3.ed. São Paulo: Loyola, 2012.

GÓMEZ DE SOUZA, L. A. O Cristão e o mundo. Petrópolis, Vozes, 1965.

- Um andarilho entre duas fidelidades: religião e sociedade. Rio de Janeiro: EDUCAM/ Ponteio, 2015.

LURO, C. El Mártir que no mataron, Hélder Câmara. Madrid: Editorial Nueva Utopia, 2002. p. 100-102.

PAULO VI, Papa. Discurso aos membros dos Institutos Seculares. Roma, 02/ 02/ 1972,

Acta Apostolicae Sedis (AAS). Città del Vaticano, 1972.

Marcelo Barros é monge beneditino da Congregação de Subiaco, Recife (PE). Foi ordenado sacerdote por Dom Helder Camara e com ele trabalhou por nove anos como assessor para o Ecumenismo e Diálogo Inter-religioso. É biblista, membro da Associação Ecumênica de Teólogos/as do Terceiro Mundo (ASETT) da qual até no início de 2018, era coordenador latino-americano. Junto com o frei Carlos Mesters, participou da equipe de biblistas que em 1979 fundaram o Centro de Estudos Bíblicos (CEBI). Durante 20 anos, foi prior do Mosteiro da Anunciação do Senhor na Cidade de Goiás, GO. Atualmente é assessor de movimentos sociais e das comunidades eclesiais de base. Email: irmarcelobarros@uol.com.br

Endereço: Rua Gervásio Fioravanti, 92, apto 403, Graças 52011-030 Recife - PE 